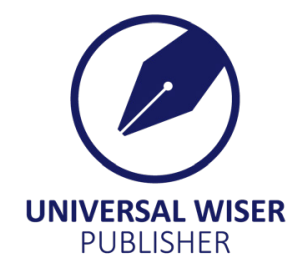

\title{
Evaluation of Postharvest Shelf Life and Quality of Lemon Treated with Different Coatings During Storage
}

\author{
Proma Sen ${ }^{1 *}$, Kazi N.S. Rafi ${ }^{1}$, Zia Uddin ${ }^{2}$, M. G. Aziz ${ }^{1}$ \\ ${ }^{1}$ Department of Food Technology and Rural Industries, Bangladesh Agricultural University, Mymensingh-2202, Bangladesh \\ ${ }^{2}$ General Manager, BRAC Dairy \& Food Project, Gazipur-1700, Bangladesh \\ E-mail: promasen47@gmail.com
}

\begin{abstract}
The effect of edible coatings such as mustard, olive and soybean oils with $1.5 \%(\mathrm{w} / \mathrm{v})$ sodium alginate $\left(\mathrm{C}_{6} \mathrm{H}_{7} \mathrm{NaO}_{6}\right)_{\mathrm{n}}$ on the postharvest shelf life and the quality of Jara Lebu (Citrus medica) in $1.5 \%$ perforated LDP (low density polythene) bags at $30-32^{\circ} \mathrm{C}$ and $80-85 \%$ relative humidity were evaluated. The changes of physico-chemical attributes like percent weight loss, percent juice yield, $\mathrm{pH}$, Total Soluble Solids (TSS), percent fruit decay, acidity and vitamin C were observed for 18 days of storage. After observing results we found that in controlling percent weight loss, percent juice yield, percent fruit decay, $\mathrm{pH}$ and TSS, mustard oil $+1.5 \%$ sodium alginate coatings showed the best results whereas soybean oil with $1.5 \%$ sodium alginate coating showed reverse results. Concerning to the results of preserving acidity and vitamin $\mathrm{C}$, the $1.5 \%$ sodium alginate and the mustard oil with $1.5 \%$ sodium alginate were found as the most effective coatings on the other hand olive oil plus $1.5 \%$ sodium alginate coatings showed slight efficiency in controlling the postharvest quality loss. Though the coating of lemon with mustard oil $+1.5 \%$ sodium alginate and only $1.5 \%$ sodium alginate showed significantly better results with respect to sensory evaluation, the former one eventually performed the best in retaining most of the quality parameters of the samples. This study clearly indicates that mustard oil with $1.5 \%$ sodium alginate coating can be used as the best edible coating for preserving almost all the postharvest quality parameters as well as extending the shelf life of Jara Lebu.
\end{abstract}

Keywords: Citrus medica, postharvest loss, edible coating, storage life, quality parameters

\section{Introduction}

Lemon (Citrus limon L.), is one of the most widely consumed citrus fruit throughout the world not only for their taste but also for the positive health values. Lemon is a rich source of bioactive substances that include vitamin $\mathrm{C}$, phenolic compounds such as hydroxyl cinnamicacids and flavonoids and it promotes good health by preventing cancer, heart disease, and other inflammatory diseases ${ }^{[1]}$. Jara Lebu (Citrus medica) is a common citron in Bangladesh ${ }^{[2]}$. Different varieties of citron are primarily known as citrus fruit in Bangladesh and West Bengal, they are collectively termed as "Lebu" or "Lemon" here ${ }^{[3]}$. After harvesting, the mature fruits become excessively soft within two to three days of storage at ambient conditions and fruits in absence of suitable post-harvest treatments become inconsumable afterwards. Despite the annual lemon production of the world is around 13.7 million tons, the post-harvest losses in lemon is about $18-25 \%{ }^{[4,5]}$. This is not promising news for the lemon cultivars. The main causes behind these losses of such nutritionally rich fruit are improper postharvest handling, microbial contamination or diseases, physiological disorders, fruit senescence and physical damages. In addition, deterioration during post-production management is also a countable cause of losing the appearance (for wilting and shriveling), texture (for softening) and degrading of nutritional quality and so on. The extension of shelf life of different produces becomes a vital need to our modern agricultural century. After harvesting, horticultural harvests remain alive and continue their respiration as part of their living system like other living produces. To perpetuate the shelf life of the lemons as long as possible, intensive care or specialized post-harvest handling practices are necessary ${ }^{[6]}$. Edible coatings are basically consumable films, which act as a defensive emollient on food circumferences ${ }^{[7]}$. It carries active ingredients such as anti-browning agents, colorants, flavors, nutrients, spices and antimicrobial compounds, to extend product shelf life and reduce the risk of pathogen growth on food surfaces ${ }^{[8-10]}$. As an environmentally conciliatory term, edible coating, superintend moisture transfer, gas exchange or oxidation processes to create an additional protective coating that provide the same effect as modified atmosphere storage by modifying internal gas composition with enhancing 
safety or even nutritional and sensory attributes ${ }^{[11]}$. Rowsni et al. ${ }^{[12]}$ investigated that, Salmonella spp showed the highest sensitivity to olive and soybean oils whereas mustard and soybean oils showed effectiveness against Staphylococcus aureus. Besides this, alginate, a salt of alginic acid, has a unique colloidal properties, by post-treatment of $\mathrm{CaCl}_{2}$ solution can form strong gels or insoluble polymers through crossed linking with $\mathrm{Ca}^{2+}$. Such biopolymer-based films could retain good quality and prolong shelf life of foods ${ }^{[13]}$. But Ramana Rao et al. suggested that a composite edible coating of sodium alginate and olive oil enriched with antioxidant is potential to control decaying incidence of Ber fruit (Ziziphus mauritiana

Lamk. Var. Gola), extends its shelf life and also improves its valuable nutritional characteristics ${ }^{[14]}$. The combined effect of alginate and different oils on reducing the postharvest loss of lemons may act as a potential tool for extending shelf life and retaining quality of lemon.

Keeping observations above in mind, this investigation has been undertaken for the following objectives: (1) To assess the effect of edible oil alone as well as combined with alginate as coating on the shelf life of Jara Lebu variety of lemons and (2) To assess the quality of treated lemons during storage.

\section{Materials and methods}

The present experiment was performed at the laboratory of the Department of Food Technology and Rural Industries, Bangladesh Agricultural University, Mymensingh.

\subsection{Collection of samples and raw materials}

The variety of Jara Lebu was used as lemon samples for the study. They were collected from a commercial garden of lemon adjacent to BAU (Bangladesh Agricultural University) campus and immediately transferred to the laboratory for setting up experiments. Mustard oil, olive oil, and soybean oil were collected from the local market for using them as coating material. Other necessary materials were obtained from laboratory stock. Only matured and uniform lemons were selected for each treatment and common maturity parameters were observed for selecting maturity. Before applying coating treatment, samples were washed very carefully with distilled water and dried them with clean and soft tissue paper so that the skin of fruits might remain intact.

\subsection{Design of experiments}

A completely randomized design was adopted to carry out the experiment where the following five coating treatments, as Table 1, were given to five groups containing five lemons in each group.

Table 1. Treatments used in the study

\begin{tabular}{ccc}
\hline No of treatments & Treatment specification & Treatments \\
\hline 1. & Control & Control (uncoated fruits) \\
2. & MO & Mustard oil with $1.5 \%$ alginate coated fruits \\
3. & OO & Olive oil with $1.5 \%$ alginate coated fruits \\
4. & SO & Soybean oil with $1.5 \%$ alginate coated fruits \\
5. & $\mathrm{AL}$ & Only $1.5 \%$ alginate coated fruits \\
\hline
\end{tabular}

Percent weight loss, percent juice yield, $\mathrm{pH}$, Total Soluble Solids (TSS), acidity, vitamin C, percent fruit decay along with sensory evaluation were assessed during storage against the above treatments as responses.

\subsection{Preparation of sodium alginate and calcium chloride solution, modified packages (MAP) and coating procedure}

According to Chiabrando and Giacalone ${ }^{[15]}, 1.5 \%$ alginate coating showed the best result in extending shelf life of nectarines and hence this concentration was used in this study. Alginate coatings were prepared following the protocol described by Rojas et al. with slight modification ${ }^{[16]}$. Firstly sodium alginate $(1.5 \% \mathrm{w} / \mathrm{v})$ was added to sterile distilled water while heating on a stirring hot plate at $70^{\circ} \mathrm{C}$ until total dissolution of the component was reached. Then the solution was cooled down to room temperature around $30^{\circ} \mathrm{C}$. Besides this, calcium chloride (food grade) at $5 \%$ (w/v) was dissolved in sterile distilled water at room temperature. For alginate coating on these oil coated fruits, it needs to wait for a few minutes to facilitate new coating. The oil coated fruits and the remaining uncoated fruits were immersed into pre-formulated $1.5 \%$ sodium alginate for $2 \mathrm{~min}$ and then dipped into $5 \%$ calcium chloride solution for 2 min to perform gelation of alginate molecules by cross-linking. The samples were then air dried at room temperature by using a table fan for at least 30 min to 
ensure the coating. LDP (low density polythene) were used as packaging materials to obtain the results of shelf life study during storage. To produce MAP (modifier atmosphere packaging), these polythene were perforated (at $1.5 \%$ ) using a borer. Then the treated samples were packed into the modified perforated polythene bags. The bags were then sealed by a mechanical sealer. Then they were stored at room temperature $\left(30-32^{\circ} \mathrm{C}\right.$ and $80-85 \%$ relative humidity) for 18 days.

\subsection{Determination of different parameter}

\subsubsection{Determination of percent weight loss}

Weight loss was measured by reassuring the reduction of weight of the treated fruits during storage. The resulting weight of the samples treated with different oils with alginate or alginate alone were taken at an interval of 3 days. The weight loss was expressed in percent. The determination of weight loss was done using the following formula (1):

Weight loss $(\%)=\frac{(B A-B K)}{B A} * 100$; here, $\mathrm{BA}=$ initial weight, $\mathrm{BK}=$ final weight.

\subsubsection{Determination of percent juice content}

The juice was extracted from the treated fruits by using a hand squeezer and then the juice was collected in a weighted empty beaker. The juice content in gram was recorded first and then percent juice yield was determined by using the following formula (2):

$$
\% \text { Juice yield }=\frac{[\text { Total weight of juice }(\mathrm{g})-\text { beaker weight }(\mathrm{g})]}{\text { Total weight of fruit }(\mathrm{g})} * 100
$$

\subsubsection{Determination of total soluble solids ( ${ }^{0}$ Brix) of juice}

Total Soluble solid of juice was measured by using a refractometer (Reichert Analytical Instruments, 2003 Brix 15HP, NY 1404, USA) and expressed in ${ }^{\circ}$ Brix. A few drops of juice were used for TSS (Total Soluble Solids) readings. For this test an average of three readings per treatment was recorded.

\subsubsection{Determination of $\mathrm{pH}$ of juice}

The $\mathrm{pH}$ value of juice of treated fruits were measured by using a digital $\mathrm{pH}$ meter (Cole Parmer, $\mathrm{Ph} 500$ series, model \#59003-20, Singapore) (AOAC method 981.12). The pH meter was immersed in the squeezed juice to record the value. From three readings per treatment, average data were recorded for this test as well.

\subsubsection{Determination of vitamin $\mathrm{C}$ (L-ascorbic acid) content in juice}

The ascorbic acid content was assessed using 2, 6-dichlorophenol indophenol dye, according to the recommended method of AOAC (2006). Sample of $5 \mathrm{~g}$ was blended and homogenized in a blender with $3 \%$ meta-phosphoric acid solution. The homogenized liquid was transferred to a $250 \mathrm{ml}$ volumetric flask and made up to $100 \mathrm{ml}$ volume with metaphosphoric acid solution and then filtered through Whatman no.4 filter paper. It was titrated against the dye taken in the burette till the permanent pale pink colour was obtained. The amount of ascorbic acid in the given solution was calculated by using the following formula (3):

$\mathrm{Mg}$ of ascorbic acid $/ 100 \mathrm{~g}$ of sample $=\frac{(\mathrm{T} * \mathrm{D} * \mathrm{~V} 1)}{(\mathrm{W} * \mathrm{~V} 2)} * 100$; here, $\mathrm{T}=$ Titre; $\mathrm{D}=$ dye factor;

$\mathrm{V}_{1}=$ Volume made up; $\mathrm{V}_{2}=$ Volume of sample taken for estimation;

$\mathrm{W}=$ Weight of sample taken for estimation

\subsubsection{Determination of titratable acidity in juice}

The AOAC official method 942.15 was followed in this method. Sample of $5 \mathrm{~g}$ of juice was homogenized with distilled water then transferred to a $250 \mathrm{ml}$ volumetric flask and then made up to $100 \mathrm{ml}$ with distilled water. The content of the flask was then thoroughly mixed and filtered. $5 \mathrm{ml}$ of the prepared solution was pipetted out into a clean conical flask and titrated immediately against standard $0.1 \mathrm{~N}$ sodium hydroxide using phenolphthalein indicator to obtain the first permanent pink color. The titratable acidity was calculated from the following relationship (4): 
Titratable acidity $=\frac{(\mathrm{T} * \mathrm{~N} * \mathrm{~V} 1 * \mathrm{E})}{(\mathrm{W} * \mathrm{~V} 2 * 1000)} * 100 ;$ here, $\mathrm{T}=$ Titre $\mathrm{N}=$ Normality of $\mathrm{NaOH}$;

$\mathrm{E}=$ Equivalent weight of acid; $\mathrm{V}_{1}=$ Volume made up; $\mathrm{V}_{2}=$ Volume of sample taken for estimation;

$\mathrm{W}=$ Weight of sample taken for estimation

\subsubsection{Determination of percent fruit decay}

All the samples were visually monitored by trained panelists selected from the students and the teachers of the Department of Food Technology and Rural Industries, Bangladesh Agricultural University and fruits with any symptoms of microbial incidence marked as fruit decay. The mature and fresh fruits were observed on $9^{\text {th }}$ day and $18^{\text {th }}$ day of storage for evaluating this parameter. The number of decayed fruit of each treatment was divided by the total number of fruits taken for that treatment and finally it was expressed in percentage.

\subsubsection{Sensory evaluation}

The sensory evaluation of treated and control lemon was carried out by a testing panel of 10 trained judges. All the treated lemons were evaluated for color, flavor, texture and overall acceptability after 18 days of storage periods. The panelists were trained and selected from the teachers and students of the Department of Food Technology and Rural Industries, Bangladesh Agricultural University, Mymensingh. Ten samples of treated lemons from each treatment were taken for sensory analysis and were given a three digit random number to each set of samples to make the evaluation unbiased. Sample sets were denoted as $121=\mathrm{AL}=1.5 \%$ alginate coated fruits; $213=\mathrm{SO}=$ Soybean oil with $1.5 \%$ alginate coated fruits; $312=\mathrm{OO}=$ Olive oil with $1.5 \%$ alginate coated fruits; $413=\mathrm{MO}=$ Mustard oil with $1.5 \%$ alginate coated fruits; $314=$ Control sample. All the sample sets of treated lemons were given to the panelists with a standard evaluation sheet and for statistical analysis of sensory data, a 9-point hedonic rating test was used to assess the degree of acceptability. The panelists were asked to mark samples on a 9-point hedonic scale ranging from 1 (dislike extremely) to 9 (like extremely).

\subsubsection{Statistical analysis}

Data obtained from the three replications of each experiment, were reported as mean \pm standard deviation as shown in different figures and tables. At each point of storage data, if the error bar overlaps, it means that the change is not significant. SPSS (Statistical Package for the Social Sciences) software and Microsoft Excel 2013 were used to conduct Analysis of Variance (ANOVA) on sensory evaluation data and to other statistical analysis. Comparison among treatments was evaluated using Least Significant Difference (LSD) $(p<0.05)$.

\section{Results and discussion}

The effect of three oils (mustard oil, soybean oil, olive oil) with and without sodium alginate coating on different parameters (percent weight loss, percent juice yield, $\mathrm{pH}$, total soluble solids ( ${ }^{\circ}$ Brix), acidity, vitamin (C), percent fruit decay along with sensory evaluation) of the Jara Lebu were studied. Uncoated fresh fruits were used as control.

\subsection{Percent weight loss}

The trend of percent weight loss in the lemon samples was increased during storage as shown in Figure 1. All types of edible coating treatments were found beneficial in controlling weight loss. 


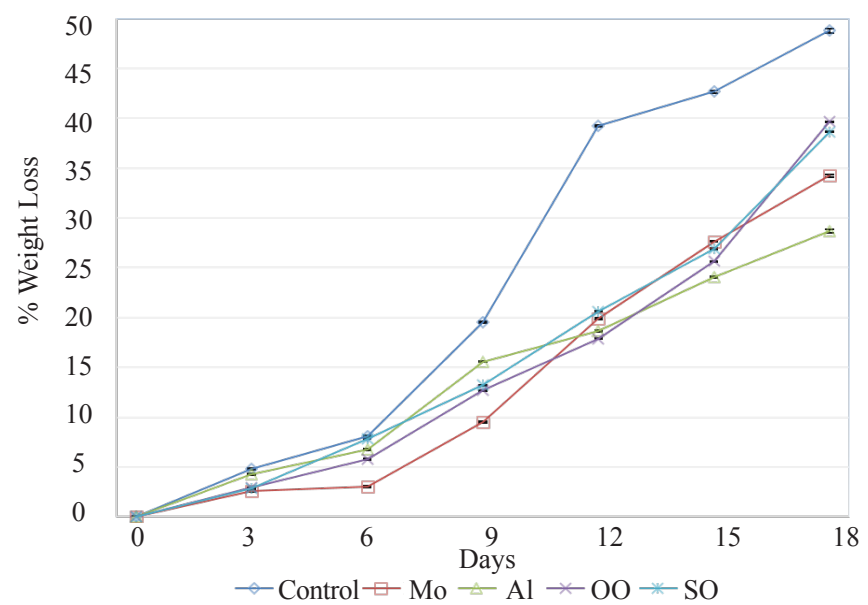

Figure 1. Effect of different coatings on \% weight loss of Jara Lebu (MO = Mustard oil with 1.5\% sodium alginate; $A L=1.5 \%$ sodium alginate; $\mathrm{SO}=$ Soybean oil with $1.5 \%$ sodium alginate; $O O=$ Olive oil with $1.5 \%$ sodium alginate) Vertical bars indicate standard deviation

As shown in Figure 1, the percentage of weight loss was significantly faster in the control samples compared to the coated samples. In the case of coated samples, despite the changes of weight loss remained closed due to the treatments, most of the cases were significantly different throughout the storage period. The treatment of mustard oil plus $1.5 \%$ sodium alginate resulted in minimum weight loss in the treated lemons up to 12 days of storage. After that $1.5 \%$ alginate coatings provided significantly lower weight loss which was about $28.65 \%$ at the end of the storage time. Among the treated samples, significantly higher weight loss was observed in olive oil and soybean oil $+1.5 \%$ sodium alginate coated samples with a figure of $39.65 \%$ and $38.65 \%$ losses, respectively. Outstanding anti-senescence characteristics of different coatings that slowed down respiratory rate, transpiration rate and binding of ethylene biosynthesis process and decreased firmness showed as the major causes of weight loss according to Bisen et al. ${ }^{[17]}$. The beneficial effect of alginate on citrus as reported by Chien et al. ${ }^{[18]}$ also supports our findings as it retained moisture in the citrus fruit by reducing the rate of transpiration and respiration. The parallel findings were also illustrated by Pandey et al. ${ }^{[19]}$ for fruits like winter guava fruits.

\subsection{Percent juice yield}

The interaction between yielding juice with different coatings on Jara Lebu during storage is shown in Figure 2. The trend of changes in percent juice yield with different treatments was decreased during storage for eighteen days.

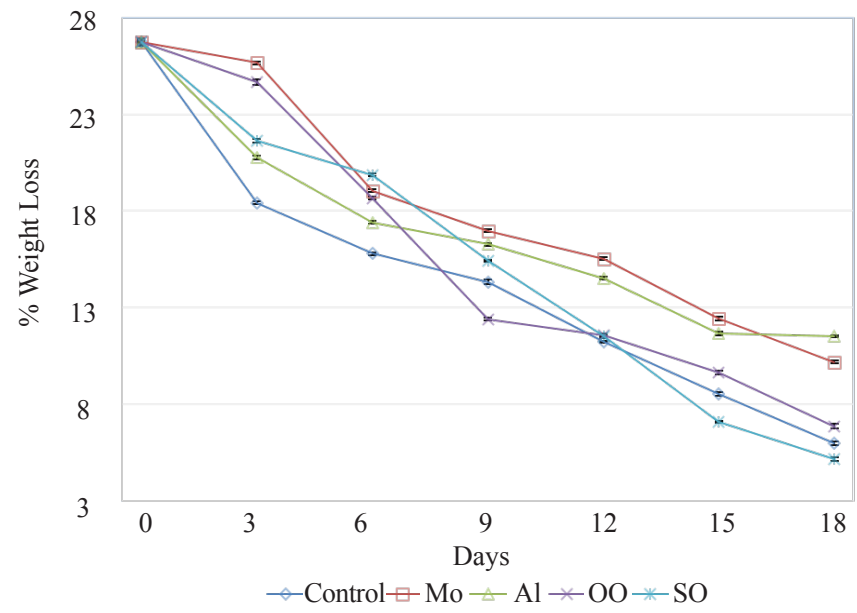

Figure 2. Effect of different coatings on percent juice yield of Jara Lebu (MO = Mustard oil with 1.5\% sodium alginate; $A \mathrm{~L}=1.5 \%$ sodium alginate; $\mathrm{SO}=$ Soybean oil with $1.5 \%$ sodium alginate; $\mathrm{OO}=$ Olive oil with $1.5 \%$ sodium alginate). Vertical bars indicate standard deviation

Mustard oil $+1.5 \%$ sodium alginate coated samples retained significantly higher juice throughout the studies compared to the other samples (Figure 2). With regard to the treated samples, soybean oil plus $1.5 \%$ sodium alginate coating resulted in maximum loss $(80.56 \%)$ in juice yield after 18 days of storage. Though on $12^{\text {th }}$ day of storage, there 
were no significant difference among soybean oil and olive oil with $1.5 \%$ sodium alginate coated samples compared to control samples, but for all other cases; significant differences were observed throughout the storage periods. The causes of this trend in juice content might be respiratory rate, transpiration rate and weight loss of samples ${ }^{[17]}$. The results of juice yield obtained for mustard oil plus $1.5 \%$ sodium alginate coating lemon samples were almost similar to the result obtained for $100 \%$ mustard oil coatings on lime fruits as reported by Bisen et al. ${ }^{[20]}$.

\subsection{Changes of samples' $\mathrm{pH}$}

The variations in $\mathrm{pH}$ for Jara Lebu due to different coating treatments are shown in Figure 3. The Figure also represents an increasing trend of $\mathrm{pH}$ for all the samples irrespective of treatment.

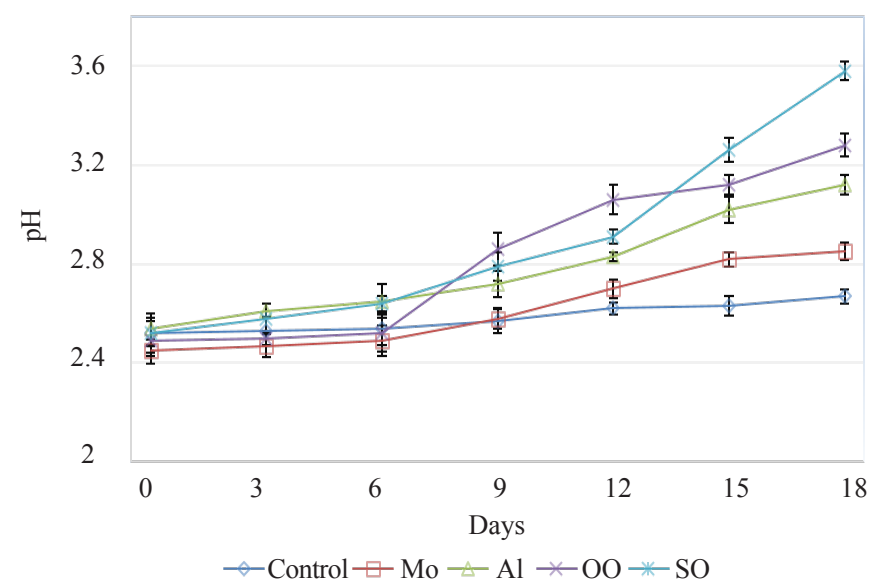

Figure 3. Effect of different coatings on pH of Jara Lebu (MO = Mustard oil with 1.5\% sodium alginate; $\mathrm{AL}=1.5 \%$ sodium alginate; $\mathrm{SO}=$ Soybean oil with $1.5 \%$ sodium alginate; $\mathrm{OO}=$ Olive oil with $1.5 \%$ sodium alginate) Vertical bars indicate standard deviation

According to Figure 3, up to $6^{\text {th }}$ day of storage, there were not much significant differences observed among the samples' $\mathrm{pH}$, but after that a significant difference was noticed for different treatments and relatively rapid changes in $\mathrm{pH}$ were occurred in olive oil and soybean oil $+1.5 \%$ sodium alginate coated samples. Among coated samples, mustard oil $+1.5 \%$ sodium alginate performed the best in retaining $\mathrm{pH}$ followed by $1.5 \%$ sodium alginate coated samples. This type of change in $\mathrm{pH}$ may happen due to the use of organic acid as a source of energy and respiration and loss of sensitive volatile components during storage. This progressive change of $\mathrm{pH}$ supports the results reported by Shahjahan et al. ${ }^{[21]}$. This occurrence might be promising due to oxidation of acid during storage resulting in higher $\mathrm{pH}$ that supports the findings of Ahmed and Singh ${ }^{[22]}$.

\subsection{Total soluble solids ( ${ }^{\circ}$ Brix)}

The changes of TSS due to different coatings' effect on the treated samples were showed in Figure 4 and an increasing trend in the changes of TSS due to different coating treatment during the storage time was observed.

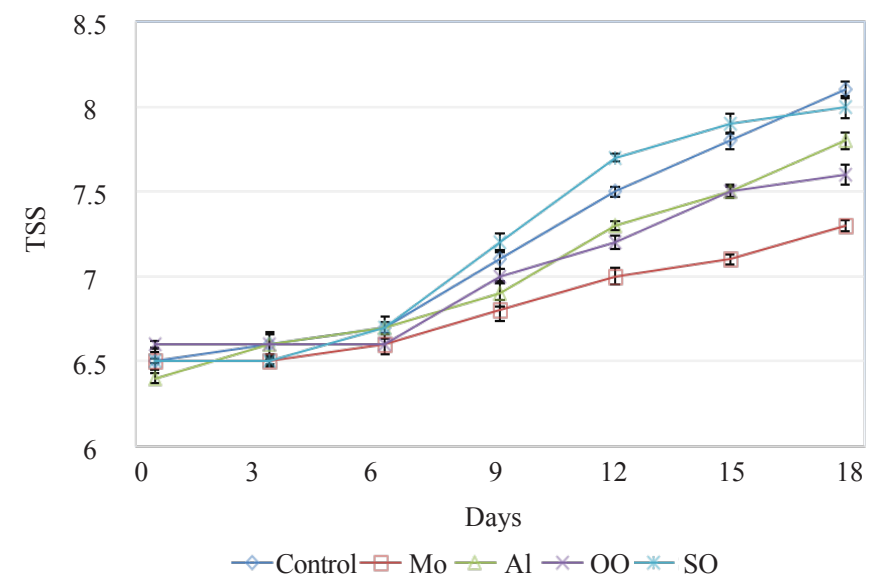

Figure 4. Effect of different coatings on TSS of Jara Lebu (MO = Mustard oil with 1.5\% sodium alginate; $\mathrm{AL}=1.5 \%$ sodium alginate; $\mathrm{SO}=$ Soybean oil with $1.5 \%$ sodium alginate; $\mathrm{OO}=\mathrm{Olive}$ oil with $1.5 \%$ sodium alginate) Vertical bars indicate standard deviation 
The TSS of lemon samples remained significantly unchanged up to six days of storage but gradually increased at the end of storage period. Among the treated samples, the mustard oil with $1.5 \%$ sodium alginate coating showed significantly lower TSS change (12.307\%) compared to other treatments. At the end of the storage periods, significant differences among the results, obtained from other treatments, were observed as well. This tended very close to the percent change due to $100 \%$ mustard oil coating in lime as reported by Bisen et al. ${ }^{[20]}$. The amount of sugar in citrus during storage increased due to cell wall hydrolysis with different enzymes which plays a significant role in increasing the level of TSS in lemon ${ }^{[23]}$. Due to decline in respiration rate by coating, the conversion of polysaccharides into soluble solid was reduced as claimed by Mastromatteo et al. ${ }^{[24]}$. Nurul et al. ${ }^{[25]}$ reported that the action of various enzymes as in the conversion of polysaccharides present in fruit to soluble sugar caused the increase of TSS in control fruits. Increasing the amount of sugar in citrus during storage might be due to cell wall hydrolysis with different enzymes ${ }^{[23,26-28]}$.

\subsection{Acidity}

The decreasing acidity of stored lemon samples represents the significant effect of different treatments as shown in Figure 5.

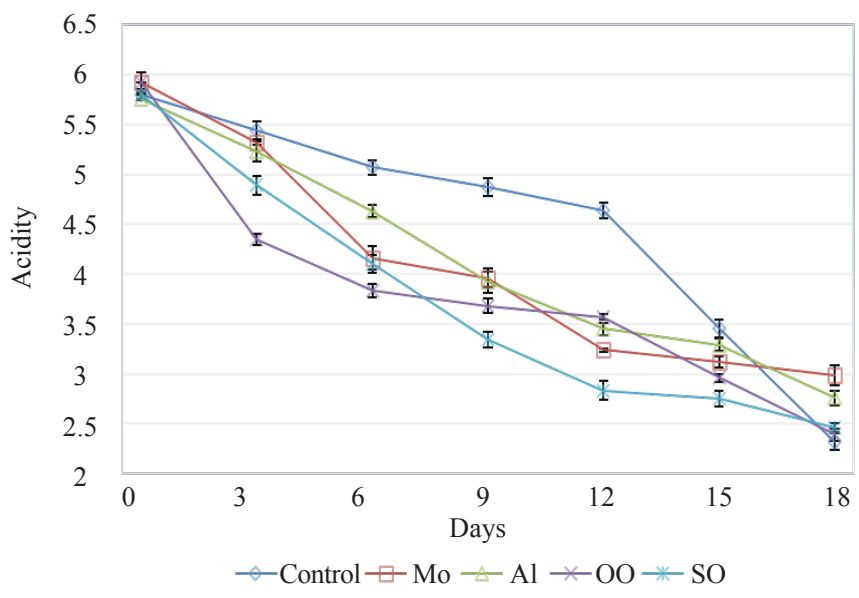

Figure 5. Effect of different coatings on acidity of Jara Lebu (MO = Mustard oil with $1.5 \%$ sodium alginate $\mathrm{AL}=1.5 \%$ sodium alginate; $\mathrm{SO}=$ Soybean oil with $1.5 \%$ sodium alginate; $\mathrm{OO}=$ Olive oil with $1.5 \%$ sodium alginate). Vertical bars indicate standard deviation

As shown in Figure 5, acidity of treated lemon samples was significantly higher than that of control samples. Among the treatments, mustard oil plus $1.5 \%$ sodium alginate was found as the significantly good coating in controlling the acidity (49.662\%) afterward storage time. But control samples got the maximum losses in acidity (60.014\%) at the end of storage and there was no significant difference among soybean oil and olive oil $+1.5 \%$ sodium alginate coated samples and control samples after storage periods. Similar results in case of the retaining acidity in fruits during storage were reported by Wills et al. ${ }^{[29]}$. Causes of such changes may happen due to the use of organic acid as a source of energy and respiration and thereby reduction in acidity percentage. The same results and the causes were described by Yaman and Bayoindirli ${ }^{[30]}$ about the decreased respiration rate and therefore interruption of the utilization of stored organic acid in the coated fruits. According to their findings, the variation of acidity among different varieties for different treatments was not the same throughout the storage period. This dissimilarity might be due to less concentration of juice as a result of dehydration of untreated samples whereas coating with oils wrapped the opening of the pore/stomata and controlled the dehydration process of treated fruits ${ }^{[31]}$.

\subsection{Vitamin C}

Ascorbic acid content ( $\mathrm{mg} / 100 \mathrm{ml}$ of juice) of stored fruits also decreased during storage. The findings of the effect of different coatings on vitamin $\mathrm{C}$ content of the treated lemons are presented in Figure 6. 


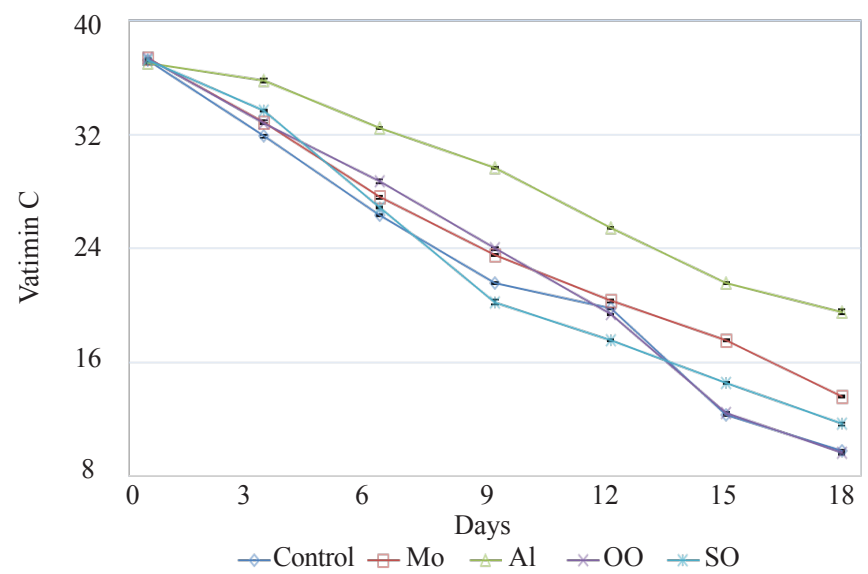

Figure 6. Effect of different coatings on vitamin C of Jara Lebu (MO = Mustard oil with $1.5 \%$ sodium alginate; $\mathrm{AL}=1.5 \%$ sodium alginate; $\mathrm{SO}=$ Soybean oil with $1.5 \%$ sodium alginate; $O O=$ Olive oil with $1.5 \%$ sodium alginate)

Vertical bars indicate standard deviation

According to Figure 6, control samples showed significant differences in ascorbic acid content compared to other coated samples. In preserving the loss of vitamin C, significantly best result was observed in the samples treated with only $1.5 \%$ sodium alginate $(47.19 \%$ loss $)$ loss followed by mustard oil plus $1.5 \%$ sodium alginate coated samples which lost about $64 \%$ vitamin C, olive oil with $1.5 \%$ sodium alginate coated samples lost $74.15 \%$ vitamin $\mathrm{C}$ throughout the storage period. Overall, samples treated by mustard oil with $1.5 \%$ sodium alginate, only $1.5 \%$ sodium alginate and soybean oil with $1.5 \%$ sodium alginate coatings showed significant difference among each other at the end of storage period. The experiential trend for reducing vitamin $\mathrm{C}$ also supports the results of declining vitamin $\mathrm{C}$ in sweet orange fruit at storage condition ${ }^{[32]}$. Mustard oil with $1.5 \%$ sodium alginate coatings showed the slower changing of vitamin $\mathrm{C}$ which was supported by the findings of Bisen et al. ${ }^{[20]}$ for $100 \%$ mustard oil coating treatments. In the content of ascorbic acid, this change might be due to metabolic changes and increase of percentage of acidity under different oils and coating types. Oils facilitated in falling the rate of respiration and maturation which resulted in dissipation of ascorbic acid to de-hydro ascorbic acid during storage ${ }^{[33]}$.

\subsection{Percent fruit decay}

Results obtained from all the treated samples clearly indicate that coated samples decayed slower than the control samples of Jara Lebu. From Figure 7, considerably minimum decay (only 13\%) was found in mustard oil with $1.5 \%$ sodium alginate coated samples whereas the maximum decay (about 80\%) was occurred in control samples after storage periods. Fruit decay in samples coated by soybean oil with $1.5 \%$ sodium alginate and olive oil with $1.5 \%$ sodium alginate showed statistically similar after eighteen days of storage. According to the investigation of Tanda-Palmu and Grosso, by delaying senescence, coatings decreased percent fruit decay. As a result of cellular or tissue integrity, senescence makes the samples more susceptible to pathogenic infection ${ }^{[34]}$ which supports the obtained result from this experiment.

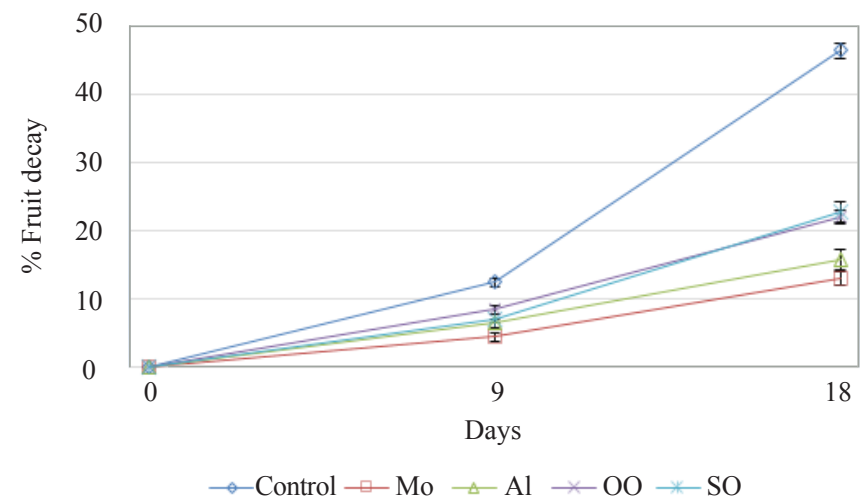

Figure 7. Effect of different coatings on percent fruit decay of Jara Lebu (MO = Mustard oil with 1.5\% sodium alginate $\mathrm{AL}=1.5 \%$ sodium alginate; $\mathrm{SO}=$ Soybean oil with $1.5 \%$ sodium alginate; $\mathrm{OO}=\mathrm{Olive}$ oil with $1.5 \%$ sodium alginate).

Vertical bars indicate standard deviation 


\subsection{Sensory evaluation}

According to Table 2, after 18 days of storage period, mustard oil $+1.5 \%$ sodium alginate and only $1.5 \%$ sodium alginate coated samples scored significantly similar results for color, flavor, texture and overall acceptability. Mustard oil with $1.5 \%$ sodium alginate coated samples secured 8 as the highest score for overall acceptance whereas control samples secured minimum scores for all the observed sensory attributes. In case of color, soybean oil $+1.5 \%$ sodium alginate and olive oil plus $1.5 \%$ sodium alginate coated samples provide statistically similar results as control samples. For retaining sensory attributes such as appearance, flavor, taste, external color, acceptable effective uses of oil emulsion coating were found for kagzi lime fruits (Citrus aurantifolia Swingle) by Bisen et al. ${ }^{[20]}$.

Table 2. Effect of different coatings on sensory attributes of treated samples

\begin{tabular}{|c|c|c|c|c|}
\hline Treatment & Color & Flavor & Texture & Overall acceptability \\
\hline Control & $1.78^{\mathrm{a}}$ & $1.44^{\mathrm{a}}$ & $2.89^{\mathrm{a}}$ & $2^{\mathrm{a}}$ \\
\hline MO & $7.44^{\mathrm{b}}$ & $7.67^{b}$ & $7.89^{b}$ & $8^{\mathrm{b}}$ \\
\hline $\mathrm{AL}$ & $6.11^{\mathrm{b}}$ & $6.89^{b}$ & $7.11^{\mathrm{b}}$ & $7.11^{\mathrm{b}}$ \\
\hline $\mathrm{OO}$ & $2.22^{\mathrm{a}}$ & $3.44^{\mathrm{c}}$ & $4.78^{c}$ & $3.11^{\mathrm{c}}$ \\
\hline SO & $2.78^{\mathrm{a}}$ & $3.67^{c}$ & $4.89^{c}$ & $3.44^{\mathrm{c}}$ \\
\hline LSD & 1.18 & 0.84 & 0.91 & 0.97 \\
\hline
\end{tabular}

Here, $\mathrm{MO}=$ Mustard oil with $1.5 \%$ sodium alginate; $\mathrm{AL}=1.5 \%$ sodium alginate; $\mathrm{SO}=$ Soybean oil with $1.5 \%$ sodium alginate; $\mathrm{OO}=$ Olive oil with $1.5 \%$ sodium alginate. Significance level: significant at $\mathrm{p}<0.05$, different superscript letters on the each column specifies significant differences, similar superscript stands for non-significances.

\section{Conclusions}

This study represents the effects of different oils (mustard, soybean and olive) plus $1.5 \%$ sodium alginate and only $1.5 \%$ sodium alginate as edible coatings on Jara Lebu which shows significantly positive effect on retaining different horticultural parameters and reducing the postharvest loss of Jara Lebu (Citrus medica) up to 18 days of storage at 30$32^{\circ} \mathrm{C}$ and $80-85 \%$ relative humidity. The study shows that almost all the treated samples showed significantly better results in preserving the shelf life and in preventing the degradation of quality parameters than the control samples. Among all the treated samples, mustard oil $+1.5 \%$ sodium alginate coated samples provides significantly superior results for minimizing percent weight loss and percent fruit decay which positively contributes to the reduction of postharvest loss of Jara Lebu whereas unexpected maximum reduction in quality attributes were observed for the samples coated with olive oil with $1.5 \%$ sodium alginate. Within all the quality parameters, especially percent juice yield, $\mathrm{pH}$, TSS were significantly controlled and showed better results by the treatment of mustard oil with $1.5 \%$ sodium alginate coatings. But in retaining vitamin $\mathrm{C}$ and acidity during storage, $1.5 \%$ sodium alginate followed by mustard oil with $1.5 \%$ sodium alginate gives the expected better result. But in some cases, soybean oil and olive oil with $1.5 \%$ sodium alginate coated samples showed significantly similar results compared to control samples. From sensory evaluation, mustard oil with $1.5 \%$ sodium alginate and only $1.5 \%$ sodium alginate coated samples provides statistically significant results for controlling color, texture, flavor and overall acceptance positively. Finally, it could be concluded that among all the edible coating treatments, mustard oil with $1.5 \%$ sodium alginate positively affects the shelf life and quality parameters in reducing the postharvest loss of Jara Lebu during storage.

\section{Acknowledgments}

Finally, the author expresses the heartiest appreciation to the Ministry of Education for providing grant for conducting the research. 


\section{References}

[1] Rapisarda P, Bellomo SE, Intrigliolo F. Anthocyanins in blood oranges: Composition and biological activity. J Agric Food Chem. 2001; 5: 217-230.

[2] Kaysar M, Hoq M, Mia M, Islam M, Islam M. An economic analysis of Jara and Colombo lemon production in Bangladesh. J Bangladesh Agric Univ. 2017; 15(2). Available from: doi: 10.3329/jbau.v15i2.35078.

[3] Wikipedia contributors. Citron. In: Wikipedia, The free encyclopedia. 2020. Available from: https://en.wikipedia.org/ w/index.php?title=Citron\&oldid $=966181297$.

[4] Sarker NI, Barman SC, Islam M, Islam R, Chakma AS. Role of lemon (Citrus limon) production on livelihoods of rural people in Bangladesh. 10.

[5] Makavana JM, Makwana PJ, Kukadiya VD, Joshi AM. Post-harvest losses of lemon fruits: An assessment of microbial floral strength during post-harvest handling. Int J Curr Microbiol Appl Sci. 2018; 7(05): 1184-1188. Available from: doi: 10.20546/ijcmas.2018.705.144.

[6] Arah IK, Ahorbo GK, Anku EK, Kumah EK, Amaglo H. Postharvest handling practices and treatment methods for tomato handlers in developing countries. Adv Agric Sci. 2016; 2016: 1-8. https://doi.org/10.1155/2016/6436945.

[7] Muranyi P. Functional edible coatings for fresh food products. J Food Process Technol. 2013; 4(1): 209.

[8] Vargas M, Chiralt A, Albors A, González-Martinez C. Effect of chitosan-based edible coatings applied by vacuum impregnation on quality preservation of fresh-cut carrot. Postharvest Biol Technol. 2008; 512: 263-271.

[9] Ricardo D, Andrade OS, Osorio FA. Atomizing spray systems for application of edible coatings. Food Sci Food Saf. 2012; 113: 323-337.

[10] Dangaran K, Tomasula PM, Qi P. Structure and function of protein-based edible films and coatings. In: Embuscado ME, Huber KC, eds. Edible Films and Coatings for Food Applications. 2nd ed. Berlin: Springer Science + Business Media, LLC; 2009. p.25-56.

[11] Dhall RK. Advances in edible coatings for fresh fruits and vegetables. Crit Rev Food Sci Nutr. 2013; 53(5): 435-450.

[12] Rowsni AA, Islam K, Md. Khan M, Md. Kabir S. Antimicrobial activity of essential oils against food-borne pathogenic bacteria. Int J Pharm Sci Res. 2014; 5(11): 4876-4879.

[13] Rhim JW. Physical and mechanical properties of water resistant sodium alginate films. LWT-Food Sci Technol. 2004; 37(3): 323-330.

[14] Ramana Rao TV, Baraiya NS, Vyas PB, Patel DM. Composite coating of alginate-olive oil enriched with antioxidants enhances postharvest quality and shelf life of Ber fruit (Ziziphus mauritiana Lamk. Var. Gola). J Food Sci Technol. 2015; 53(1): 748-756.

[15] Chiabrando V, Giacalone G. Effects of edible coatings on quality maintenance of dresh-cut nectarines. Emir J Food Agric. 2016; 28(3): 201. Available from: doi: 10.9755/ejfa.2015-09-771.

[16] Rojas-Graü MA, Soliva-Fortuny R, Martin-Belloso O. Edible coatings: past, present and future. Stewart Postharvest Rev. 2010; 6(3): 1-5. Available from: doi:10.2212/spr.2010.3.1

[17] Bisen A, Pandey SK, Joushwa JE. Effect of gamma irradiation, growth retardant and coatings on storability of lime fruits. Asian J Hort. 2008; 25: 159-163.

[18] Chien PJ, Sheu F, Lin HR. Coating citrus (Murcotttangor) fruit with low molecular weight chitosan increases postharvest quality and shelf life. Food Chem. 2007; 100: 1160.

[19] Pandey SK, Joshua JE, Bisen A. Influence of gamma-irradiation, growth retardants and coatings on the shelf life of winter guava fruits (Psidium guajava L.). J Food Sci Technol. 2010; 47(1): 124-127.

[20] Bisen A, Pandey SK, Patel N. Effect of skin coatings on prolonging shelf life of kagzi lime fruits (Citrus aurantifolia Swingle). J Food Sci Technol. 2011; 49(6): 753-759. Available from: doi: 10.1007/s13197-010-0214-y.

[21] Shahjahan MS, Sheel MA, Zaman MA, Sakur MA. Optimization of harvesting maturities for major mango cultivars in Bangladesh. Bangladesh J Sci Ind Res. 1994; 12: 209-215.

[22] Ahmed MS, Singh S. Studies on extension of storage life of Amrupali mango. Orissa J Hortic. 2000; 28: 73-76.

[23] Chundawat BS, Singh HK, Gupta OP. Effect of different methods of ripening in guava (Psidium guajava L) onquality of fruits. Haryana J Hort Sci. 1978; 7(2): 28-30.

[24] Mastromatteo M, Conte A, Nobile MA. Combined effect of active coating and MAP to prolong the shelf life of minimally processed kiwifruit. Food Res Int. 2010; 44: 1224-1230.

[25] Nurul HMZ, Zahrah HMS, Zaibunnisa AH. Effect of chitosan-palm stearin edible coating on the post-harvest life of star fruits (Averrhoa carambola L.) stored at room temperature. Int Food Res J. 2012; 19(4): 1433-1438.

[26] Echeverria E, Burns JK, Wicker L. Effect of cell wall hydrolysis on Brix in citrus fruit. Proc Fla State Hort Soc. 1988; 101: $150-154$.

[27] Golshan TA, Shahbik M. Effect of physical and chemical treatments in storage of Valencia oranges. Mars ErlyandJiroft local. J Iran Agric Sci. 2004; 35(3): 720-713. 
[28] Obenland D, Collin S, Sievert J, Fjeld K, Doctor J, Arpaia ML. Commercial packing and storage of navel oranges alters aroma volatiles and reduces flavor quality. J Postharvest Biol Technol. 2008; 47(2): 159-167.

[29] Wills RBH, Mc-Glasson B, Graham D, Joyce D. Postharvest: An Introduction to the Physiology and Handling of Fruits, Vegetables and Ornamentals. 4th ed. UNSW Press; 1998.

[30] Yaman OL, Bayoindirli L. Effects of an edible coating and cold storage on shelf-life and quality of cherries. Lwt-Food Sci Technol. 2002; 35: 146-150.

[31] Kulkarni SG, Vijayanand P, Shubha L. Effect of processing of dates into date juice concentrate and appraisal of its quality characteristics. J Food Sci Technol. 2010; 47(2): 157-161.

[32] Rab A, Najia M, Sajid, et al. Quality changes in heat treated sweet orange fruit during storage at low temperature. $J$ Anim Plant Sci. 2015; 25(3): 661-668.

[33] El-Monem EAAA, Mostafa A, El-Maged MAA. Effect of harvest treatments on storage behavior of guava fruits cv. Sardar. J Maharashtra Agric Univ. 2003; 26: 297-300.

[34] Tanada-Palmu PS, Grosso CRF. Effect of edible wheat gluten-based films and coatings on refrigerated strawberry (Fragaria ananassa) quality. Postharvest Biol Technol. 2005; 36(2): 199-208. Available from: doi: 10.1016/j.postharvbio.2004.12.003. 